OPEN ACCESS

Edited by:

Athanassios Argiris,

Thomas Jefferson University,

United States

Reviewed by:

Yiyi Chen,

Oregon Health \& Science University,

United States

Giuseppe Giaccone,

Independent Researcher, Namur,

Belgium

*Correspondence:

Olgun Elicin

olgun.elicin@insel.ch

Specialty section:

This article was submitted to

Head and Neck Cancer.

a section of the journal

Frontiers in Oncology

Received: 26 April 2019 Accepted: 09 October 2019

Published: 24 October 2019

Citation:

Broglie MA, Dulguerov P, Henke G,

Siano M, Putora PM, Simon C,

Zwahlen D, Huber GF, Ballerini G,

Beffa L, Giger R, Rothschild S,

Negri SV and Elicin O (2019) A Review

of Controversial Issues in the

Management of Head and Neck Cancer: A Swiss Multidisciplinary and

Multi-Institutional Patterns of Care

Study - Part 4 (Biomarkers)

Front. Oncol. 9:1128.

doi: 10.3389/fonc.2019.01128

\section{A Review of Controversial Issues in the Management of Head and Neck Cancer: A Swiss Multidisciplinary and Multi-Institutional Patterns of Care Study-Part 4 (Biomarkers)}

\author{
Martina A. Broglie 1,2, Pavel Dulguerov ${ }^{3}$, Guido Henke ${ }^{4}$, Marco Siano ${ }^{5,6}$, \\ Paul Martin Putora ${ }^{4,7}$, Christian Simon ${ }^{8}$, Daniel Zwahlen ${ }^{9,10}$, Gerhard F. Huber ${ }^{1,2}$, \\ Giorgio Ballerini ${ }^{11}$, Lorenza Beffa ${ }^{12}$, Roland Giger ${ }^{13}$, Sacha Rothschild ${ }^{14}$, Sandro V. Negri ${ }^{15}$ \\ and Olgun Elicin ${ }^{7 *}$
}

\begin{abstract}
1 Department of Otorhinolaryngology, Head and Neck Surgery, Cantonal Hospital St. Gallen, St. Gallen, Switzerland, ${ }^{2}$ Department of Otorhinolaryngology, Head and Neck Surgery, University Hospital Zurich, Zurich, Switzerland, ${ }^{3}$ Department of Otorhinolaryngology, Head and Neck Surgery, Geneva University Hospital, Geneva, Switzerland, ${ }^{4}$ Department of Radiation Oncology, Cantonal Hospital St. Gallen, St. Gallen, Switzerland, ${ }^{5}$ Department of Medical Oncology, Cantonal Hospital St. Gallen, St. Gallen, Switzerland, ${ }^{6}$ Department of Medical Oncology, Hôpital Riviera-Chablais, Vevey, Switzerland, ${ }^{7}$ Department of Radiation Oncology, Inselspital, Bern University Hospital, University of Bern, Bern, Switzerland, ${ }^{8}$ Department of Otorhinolaryngology, Head and Neck Surgery, University Hospital of Lausanne, Lausanne, Switzerland, ${ }^{9}$ Department of Radiation Oncology, Cantonal Hospital Graubünden, Chur, Switzerland, ${ }^{10}$ Department of Radiation Oncology, Cantonal Hospital of Winterthur, Winterthur, Switzerland, ${ }^{11}$ Department of Radiation Oncology, Clinica Luganese SA, Lugano, Switzerland, ${ }^{12}$ Department of Radiation Oncology, Cantonal Hospital Lucerne, Lucerne, Switzerland, ${ }^{13}$ Department of Otorhinolaryngology, Head and Neck Surgery, Inselspital, Bern University Hospital, Bern, Switzerland, ${ }^{14}$ Department of Medical Oncology, University Hospital of Basel, Basel, Switzerland, ${ }^{15}$ Department of Otorhinolaryngology, Lindenhofspital, Bern, Switzerland
\end{abstract}

Background: The Head and Neck Cancer Working Group of Swiss Group for Clinical Cancer Research (SAKK) has investigated the level of consensus (LOC) and discrepancy in everyday practice of diagnosis and treatment in head and neck cancer.

Materials and Methods: An online survey was iteratively generated with 10 Swiss university and teaching hospitals. LOC below 50\% was defined as no agreement, while higher LOC were arbitrarily categorized as low (51-74\%), moderate (75-84\%), and high ( $\geq 85 \%)$.

Results: Any LOC was achieved in $62 \%$ of topics $(n=60)$. High, moderate, and low LOC were found in 18, 20, and 23\%, respectively. Regarding Head and Neck Surgery, Radiation Oncology, Medical Oncology, and biomarkers, LOC was achieved in 50, 57, 83 , and $43 \%$, respectively.

Conclusions: Consensus on clinical topics is rather low for surgeons and radiation oncologists. The questions discussed might highlight discrepancies, stimulate standardization of practice, and prioritize topics for future clinical research.

Keywords: consensus, head and neck cancer, patterns of care, practice patterns, survey 


\section{INTRODUCTION}

This is the fourth part of the article "A Review of Controversial Issues in the Management of Head and Neck Cancer: A Swiss Multidisciplinary and Multi-Institutional Patterns of Care Study," providing the results for the items concerning biomarkers, each followed by a short discussion if deemed relevant. The details of the methodology is presented in the first part of this series.

\section{RESULTS AND DISCUSSION OF BIOMARKERS WITH CURRENT POTENTIAL USE}

\section{- Imaging findings indicating hypoxia and/or central necrosis are not standard factors influencing the treatment decision: no consensus.}

In 5/10 centers, imaging findings indicating hypoxia or central necrosis affects the decision for the primary treatment modality.

According to the literature (1), tumor hypoxia can be associated with aggressive tumor phenotype affecting the natural course of disease in these patients (2) due to assumed radiotherapy resistance. Based on laboratory experience, a up to three times higher photon radiation dose is needed to cause the same cytotoxic effect in hypoxic cells compared to normal tumor cells (3). Whether such dose escalation could be performed, while keeping low toxicity rates in normal tissue is questionable (4). The advantage of dose escalation to hypoxic sub-volumes with conventional photon radiation has been analyzed in clinical practice to overcome this bad prognostic factor (5-8). However, the clinical identification, measurement, and localization of hypoxia in tumors remain debatable. The studies range from noninvasive clinical assumptions to direct measurements with oxygen electrodes, and indirect methods such as serum biomarkers or immunohistochemistry (IHC) of hypoxia-related markers. There has been found a significant heterogeneity in regional oxygenation as well as in biological response to hypoxia confounding these tissue-sampling methods. In current clinical practice, boost dose is guided by CT scans and is based primarily on size criteria (1). However, the correlation between tumor hypoxia and common clinical parameters such as size, morphology, and histology is scarce (9). PET scans could deliver more functional information based on tumor metabolism (10).

In tumors with presence of diffuse hypoxia a systemic approach using a hypoxic cell cytotoxin or anti-growth factor drugs might be beneficial to overcome the limitations of hypoxia (11). Alternatively, in a more focal hypoxia a local/regional approach, such as IMRT-based radiation dose escalation to the hypoxic sub-volume might be more successful $(12,13)$. In different studies, the complementary role of radiation and systemic hypoxia-specific pro-drugs to overcome the hypoxiainduced resistance has been established $(14,15)$. Furthermore, there is a higher risk for persistence of hypoxic tumors after primary CRT and the timing of salvage surgery such as planned neck dissection should be adapted.

Anyhow, regarding the limited evidence for the role of imaging findings indicating hypoxia, it is quite remarkable that half of the centers in Switzerland integrate them in treatment decisions.

\section{$>$ De-differentiation grade is not a standard factor influencing the treatment decision: no consensus.}

De-differentiation grade of tumors also influences treatment decision in 5/10 centers. This question did not differ between squamous cell cancer and other malignancies of the head and neck.

In salivary gland carcinoma, the histologic grade is a significant predictor of treatment response and an established factor for therapeutic decisions, but due to the rarity and wide variety of different tumor types the definition of predictive grading schemes is challenging (16).

In HNSCC, histologic grade is not part of the current staging criteria, probably because its prognostic impact remains controversial. Weijers et al. (17) found no significant correlation between grade and prognosis in early stage oral cancer. In contrast, other studies (18-20) found a significant impact of tumor differentiation and staging on recurrence and overall survival. Furthermore, a recent study (21) in early stage oral cancer has demonstrated a strong association between histologic grade and survival. High histologic grade was associated with poorer survival and carried an independent prognostic value in addition to tumor size, node status, and presence of distant metastasis (TNM) stage (21). Even though grade is not part of the UICC staging system, some centers do consider high grade as an indication for adjuvant treatment $(22,23)$.

$>$ Determining the HPV status is a standard practice in oropharyngeal squamous cell carcinoma (OPSCC): high LOC (100\%).

$>$ There is no standard method established for the definition of HPV status: no consensus.

All (10/10) centers regularly determine the HPV status in OPSCC. The definition of an HPV attributable tumor is IHC overexpression of p16 as a single marker ( 5 centers), HPV highrisk type DNA positivity by polymerase chain reaction (PCR) (2 centers); HPV high risk type DNA positivity by ISH (1 center) and p16, followed by PCR if needed according to College of American Pathologists guidelines (1 center).

The survey was performed prior to the release of the 8th edition of the UICC TNM classification system, implementing p16 IHC as a crucial biomarker for staging of OPSCC. Nevertheless, all centers had already started to routinely determine the HPVstatus in OPSCC. Interestingly, the definition of a positive HPVstatus widely differs between the centers, reflecting the lack of a worldwide-accepted consensus for the accurate definition of an HPV-driven cancer. In the new UICC staging system (8th edition), p16 is accepted for practical and cost-related reasons considering the guideline to be international (24), but the definition of a high-risk HPV-attributed cancer is still a matter of debate (25).

Currently, detection of $\mathrm{p} 16^{\mathrm{INK} 4 \mathrm{~A}}$ (inhibitor of cyclindependent kinase 4) overexpression in tumor tissue by IHC is used as a surrogate marker for HPV-driven HNSCC (26). However, p16 ${ }^{\text {INK4A }}$ IHC as a single diagnostic marker has shown insufficient sensitivity (27-30) and specificity $(27,29-31)$.

Due to its high sensitivity, high-risk HPV-DNA detection by quantitative PCR has been commonly employed to detect 
HPV-driven tumors, but was found to lack sufficient specificity, which could lead to false positive results (32). Indeed, HPVDNA detection in tumor specimens is not proving a causal viral association of carcinogenesis but could also be the result of a past non-transforming HPV-infection or contamination (33). Detection of the transcripts of viral oncogenes E6 and E7 in tumor through mRNA techniques is widely accepted as gold standard for determining the oncogenic role of HPV in tumor. However, extraction techniques and analyses of RNA from the routinely available formalin-fixed paraffin-embedded tissue specimens remain challenging and costly, limiting their widespread use (27). In this context, Smeets et al. (31) validated an algorithm based on the combination of $\mathrm{p} 16^{\mathrm{INK} 4 \mathrm{~A}}$ IHC followed by HPV-DNA analysis to detect an oncogenically active HPV infection in formalin-fixed paraffin-embedded tissue specimens: the accuracy, sensitivity, and specificity were 98,96 , and $98 \%$, respectively when compared to RNA detection (34), that is why it would probably be the most suitable definition for tumoral $\mathrm{HPV}$-association in clinical routine.

- Most centers determine the HPV status in a carcinoma of unknown primary (CUP): low LOC (60\%).

In $6 / 10$ centers, HPV status is routinely determined in lymph node metastases without evidence of a primary tumor.

Cervical lymph node metastases from clinically undetectable primary squamous cell carcinoma present a diagnostic and therapeutic challenge. There is no clear consensus for the optimal treatment in CUP. Recommendations range from surgery of the neck alone to primary radiotherapy of the mucosa at risk and both neck sides (35-39). In the era of treatment de-intensification, the potential benefit of radiotherapy of putative primary tumor sites has to be weighed against its detrimental effect on quality of life and additional toxicity. The role of high-risk HPV infection in the development of HNSCC has gained evidence $(40,41)$, in particular for CUP. Several studies showed a high correlation between HPV-positive lymph node metastases and the detection of the primary tumor in the oropharynx. Many HPV-associated tumors present with prominent nodal disease and small, difficult or even undetectable (clinically and radiologically) primaries hidden in palatine and lingual tonsillar crypts (42). Therefore, a rising incidence of HPV-positive lymph node metastases manifesting as CUP has been reported (43-46). Unfortunately the sensitivity of ${ }^{18}$ FDG-PET/CT is adversely affected by false positives from hypermetabolic oropharyngeal lymphoid tissue (42). Even in patients with CUP HPV-positivity in lymph node metastases is a positive prognostic factor and influencing treatment decisions (47). This was accounted for in the updated 8th edition of the UICC classification by integrating HPVpositivity of the primary tumor or the lymph node metastases in CUP staging. Since the survey was performed prior to the release of the 8th edition of the UICC TNM classification system it is interesting to see, that at that time the importance of HPV infection in CUP was not evident in $40 \%$ of the centers in Switzerland.

After an intensive literature search in Pubmed and Medline we have only found one comparable survey about patterns of care for CUP. It has been performed recently in Germany, only included radiation oncologists and has revealed that $82 \%$ of the departments routinely determined HPV status in CUP (48). This rate is significantly higher than in Switzerland. According to the authors it is explained by the requirements to stage a CUP according to the 8th TNM-classification edition and known as an increasingly important prognostic factor.

$>$ Determination of the HPV status in non-oropharyngeal HNSCC is not accepted as a standard practice: no consensus.

HPV status is also determined in non-oropharyngeal primaries in $4 / 10$ centers.

This question is related to whether the presence of HPV in nonoropharyngeal HNSCC represent viral-mediated carcinogenesis, or merely a "bystander" infection and whether HPV-positivity in such cases influences the treatment strategy and clinical outcome (49). Large data on HPV DNA detection by PCR and p16 expression in HNSCC biopsies suggests that the probability of a cancer of the oral cavity, larynx, and hypopharynx being attributable to HPV is at least 5-fold lower than that for OPSCC $(49,50)$. High-risk HPV DNA was also detected in a significant proportion of sinonasal, nasopharyngeal, and salivary gland cancers, but the clinical significance of these findings in these malignancies has not been clearly defined. Limited data on HPV E6/E7 mRNA suggests that HPV-attributable HNSCC is rare in the oral cavity (3\%), larynx (7\%) and lacking in the hypopharynx (0\%). Concerning the prognostic impact of HPV-positivity in non-oropharyngeal subsites, no data currently supports that HPV is significantly associated with improved outcome in oral or laryngeal cancer (49), while data are lacking for other subsites (49). In the absence of appropriately powered, well-designed studies, HPV-detection in non-oropharyngeal sites does not seem to impact staging or treatment.

> Most centers do not base their treatment decision on HPV status: moderate LOC (80\%).

HPV status does not influence the treatment decision in $8 / 10$ centers. Two centers stated that they may consider changing the treatment intensity.

Although HPV-positivity in OPSCC is an established positive prognostic marker, treatment decisions should so far not be influenced by it. There is a lot of ongoing discussion about treatment de-escalation in this low-risk tumor but centers should wait for the shortcoming results of prospective clinical trials to decide on less intensive treatment regimen.

\section{SUMMARY}

In summary, there is no consensus regarding the applicability of imaging findings indicating hypoxia as well as histological differentiation grade. In all centers, the determination of the HPV-status is a standard practice in oropharyngeal squamous cell carcinoma rather than in cancer of unknown primary. Since the survey was performed prior to the release of the 8th edition of the UICC TNM classification system it is interesting to see, that at that time the importance of HPV infection especially in CUP was not evident in almost half of the centers in Switzerland.

Furthermore, there is a lack of standard method established for the definition of $\mathrm{HPV}$-status ranging from p16 IHC as a single marker, HPV-DNA by PCR or ISH as single 
markers or the combination of both reflecting the lack of a worldwide-accepted consensus for the accurate definition of an HPV-driven cancer. In the majority of centers, there is no therapeutic consequence of HPV-testing in both OPSCC and CUP due to lack of practice guidelines based on prospective clinical trials.

\section{CONCLUSION}

The findings of our survey indicate a low LOC among head and neck oncologists working in academic and multidisciplinary setting in 10 Swiss institutions. The highest LOC was achieved among medical oncologists, whereas the lowest was observed among head and neck surgeons. On the other hand, this level of disagreement may also depend on the topics chosen for the survey, and not necessarily the heterogeneity within the disciplines. It is also interesting to witness a low LOC regarding topics, where a high level of evidence actually does exist, and vice versa. This article is expected to serve the head and neck oncologists to be aware of their discrepancies and to stimulate

\section{REFERENCES}

1. Hendrickson K, Phillips M, Smith W, Peterson L, Krohn K, Rajendran J. Hypoxia imaging with [F-18] FMISO-PET in head and neck cancer: potential for guiding intensity modulated radiation therapy in overcoming hypoxia-induced treatment resistance. Radiother Oncol. (2011) 101:36975. doi: 10.1016/j.radonc.2011.07.029

2. Rajendran JG, Schwartz DL, O’Sullivan J, Peterson LM, Ng P, Scharnhorst J, et al. Tumor hypoxia imaging with [F-18] fluoromisonidazole positron emission tomography in head and neck cancer. Clin Cancer Res. (2006) 12:5435-41. doi: 10.1158/1078-0432.CCR-05-1773

3. Evans SM, Koch CJ. Prognostic significance of tumor oxygenation in humans. Cancer Lett. (2003) 195:1-16. doi: 10.1016/S0304-3835(03)00012-0

4. Wang JZ, Li XA, Mayr NA. Dose escalation to combat hypoxia in prostate cancer: a radiobiological study on clinical data. Br J Radiol. (2006) 79:90511. doi: $10.1259 / \mathrm{bjr} / 18700614$

5. Rajendran JG, Hendrickson KRG, Spence AM, Muzi M, Krohn KA, Mankoff DA. Hypoxia imaging-directed radiation treatment planning. Eur J Nucl Med Mol Imaging. (2006) 33 (Suppl 1):44-53. doi: 10.1007/s00259-006-0135-1

6. Thorwarth D, Eschmann S-M, Paulsen F, Alber M. Hypoxia dose painting by numbers: a planning study. Int J Radiat Oncol Biol Phys. (2007) 68:291300. doi: 10.1016/j.ijrobp.2006.11.061

7. Lee NY, Mechalakos JG, Nehmeh S, Lin Z, Squire OD, Cai S, et al. Fluorine-18-labeled fluoromisonidazole positron emission and computed tomography-guided intensity-modulated radiotherapy for head and neck cancer: a feasibility study. Int J Radiat Oncol Biol Phys. (2008) 70:213. doi: 10.1016/j.ijrobp.2007.06.039

8. Chao KS, Bosch WR, Mutic S, Lewis JS, Dehdashti F, Mintun MA, et al. A novel approach to overcome hypoxic tumor resistance: Cu-ATSM-guided intensity-modulated radiation therapy. Int J Radiat Oncol Biol Phys. (2001) 49:1171-82. doi: 10.1016/S0360-3016(00)01433-4

9. Adam MF, Gabalski EC, Bloch DA, Oehlert JW, Brown JM, Elsaid AA, et al. Tissue oxygen distribution in head and neck cancerpatients. Head Neck. (1999) 21:146-53. doi: 10.1002/(SICI)1097-0347(199903)21:2<146::AIDHED8>3.0.CO2;-U

10. Svensson H, Ringborg U, Näslund I, Brahme A. Development of light ion therapy at the Karolinska Hospital and Institute. Radiother Oncol. (2004) 73 (Suppl 2):S206-10. doi: 10.1016/S0167-8140(04)80049-5

11. Brown JM. Therapeutic targets in radiotherapy. Int J Radiat Oncol Biol Phys. (2001) 49:319-26. doi: 10.1016/S0360-3016(00)01482-6 discussion toward standardization of practice and prioritize topics of future clinical research.

\section{DATA AVAILABILITY STATEMENT}

All datasets generated for this study are included in the manuscript/supplementary files.

\section{AUTHOR CONTRIBUTIONS}

GH, MB, OE, PD, and PP: conception and design. OE and PP: collection of data. Generation of the initial and final versions of the questions, drafting of the manuscript, and approval of the final version by all co-authors.

\section{ACKNOWLEDGMENTS}

We thank each of our colleagues working with the local coordinators for filling out the part of the questionnaire corresponding to their area of expertise in their institution.

12. Gregoire V, Langendijk JA, Nuyts S. Advances in radiotherapy for head and neck cancer. J Clin Oncol. (2015) 33:3277-84. doi: 10.1200/JCO.2015.61.2994

13. Löck S, Perrin R, Seidlitz A, Bandurska-Luque A, Zschaeck S, Zöphel $\mathrm{K}$, et al. Residual tumour hypoxia in head-and-neck cancer patients undergoing primary radiochemotherapy, final results of a prospective trial on repeat FMISO-PET imaging. Radiother Oncol. (2017) 124:53340. doi: 10.1016/j.radonc.2017.08.010

14. Overgaard J. Hypoxic radiosensitization: adored and ignored. J Clin Oncol. (2007) 25:4066-74. doi: 10.1200/JCO.2007.12.7878

15. Overgaard J. Hypoxic modification of radiotherapy in squamous cell carcinoma of the head and neck-a systematic review and meta-analysis. Radiother Oncol. (2011) 100:22-32. doi: 10.1016/j.radonc.2011.03.004

16. Seethala RR. An update on grading of salivary gland carcinomas. Head Neck Pathol. (2009) 3:69-77. doi: 10.1007/s12105-009-0102-9

17. Weijers M, Snow GB, Bezemer PD, van der Waal I. Malignancy grading is no better than conventional histopathological grading in small squamous cell carcinoma of tongue and floor of mouth: retrospective study in 128 patients. $J$ Oral Pathol Med. (2009) 38:343-7. doi: 10.1111/j.1600-0714.2009.00751.x

18. Roland NJ, Caslin AW, Nash J, Stell PM. Value of grading squamous cell carcinoma of the head and neck. Head Neck. (1992) 14:2249. doi: 10.1002/hed.2880140310

19. Piffkò J, Bànkfalvi A, Ofner D, Bryne M, Rasch D, Joos U, et al. Prognostic value of histobiological factors (malignancy grading and AgNOR content) assessed at the invasive tumour front of oral squamous cell carcinomas. $\mathrm{Br}$ J Cancer. (1997) 75:1543-6. doi: 10.1038/bjc.1997.263

20. Brandwein-Gensler M, Teixeira MS, Lewis CM, Lee B, Rolnitzky L, Hille JJ, et al. Oral squamous cell carcinoma: histologic risk assessment, but not margin status, is strongly predictive of local disease-free and overall survival. Am J Surg Pathol. (2005) 29:167-78. doi: 10.1097/01.pas.0000149687.90710.21

21. Thomas B, Stedman M, Davies L. Grade as a prognostic factor in oral squamous cell carcinoma: a population-based analysis of the data. Laryngoscope. (2014) 124:688-94. doi: 10.1002/lary.24357

22. Grimm M. Prognostic value of clinicopathological parameters and outcome in 484 patients with oral squamous cell carcinoma: microvascular invasion $(\mathrm{V}+)$ is an independent prognostic factor for OSCC. Clin Transl Oncol. (2012) 14:870-80. doi: 10.1007/s12094-012-0867-2

23. Kademani D, Bell RB, Bagheri S, Holmgren E, Dierks E, Potter B, et al. Prognostic factors in intraoral squamous cell carcinoma: the influence of histologic grade. J Oral Maxillofac Surg. (2005) 63:1599605. doi: 10.1016/j.joms.2005.07.011 
24. Lydiatt WM, Patel SG, O'Sullivan B, Brandwein MS, Ridge JA, Migliacci JC, et al. Head and Neck cancers-major changes in the American Joint Committee on cancer eighth edition cancer staging manual. CA Cancer J Clin. (2017) 67:122-37. doi: 10.3322/caac.21389

25. Boscolo-Rizzo P, Pawlita M, Holzinger D. From HPV-positive towards HPVdriven oropharyngeal squamous cell carcinomas. Cancer Treat Rev. (2016) 42:24-9. doi: 10.1016/j.ctrv.2015.10.009

26. Klaes R, Friedrich T, Spitkovsky D, Ridder R, Rudy W, Petry U, et al. Overexpression of p16(INK4A) as a specific marker for dysplastic and neoplastic epithelial cells of the cervix uteri. Int J cancer. (2001) 92:27684. doi: 10.1002/ijc.1174

27. Holzinger D, Schmitt M, Dyckhoff G, Benner A, Pawlita M, Bosch FX. Viral RNA patterns and high viral load reliably define oropharynx carcinomas with active HPV16 involvement. Cancer Res. (2012) 72:49935003. doi: 10.1158/0008-5472.CAN-11-3934

28. Begum S, Cao D, Gillison M, Zahurak M, Westra WH. Tissue distribution of human papillomavirus 16 DNA integration in patients with tonsillar carcinoma. Clin Cancer Res. (2005) 11:5694-9. doi: 10.1158/1078-0432.CCR-05-0587

29. Hoffmann M, Tribius S, Quabius ES, Henry H, Pfannenschmidt S, Burkhardt C, et al. HPV DNA, E6*I-mRNA expression and p16INK4A immunohistochemistry in head and neck cancer how valid is p16INK4A as surrogate marker? Cancer Lett. (2012) 323:88-96. doi: 10.1016/j.canlet.2012.03.033

30. Smith EM, Wang D, Kim Y, Rubenstein LM, Lee JH, Haugen TH, et al. P16INK4a expression, human papillomavirus, and survival in head and neck cancer. Oral Oncol. (2008) 44:133-42. doi: 10.1016/j.oraloncology.2007.01.010

31. Smeets SJ, Hesselink AT, Speel E-JM, Haesevoets A, Snijders PJF, Pawlita $\mathrm{M}$, et al. A novel algorithm for reliable detection of human papillomavirus in paraffin embedded head and neck cancer specimen. Int J cancer. (2007) 121:2465-72. doi: 10.1002/ijc.22980

32. van den Brule AJC, Pol R, Fransen-Daalmeijer N, Schouls LM, Meijer CJLM, Snijders PJF. GP5+/6+ PCR followed by reverse line blot analysis enables rapid and high-throughput identification of human papillomavirus genotypes. J Clin Microbiol. (2002) 40:779-87. doi: 10.1128/JCM.40.3.779-787.2002

33. Jung AC, Briolat J, Millon R, de Reyniès A, Rickman D, Thomas E, et al. Biological and clinical relevance of transcriptionally active human papillomavirus (HPV) infection in oropharynx squamous cell carcinoma. Int J cancer. (2010) 126:1882-94. doi: 10.1002/ijc.24911

34. Rietbergen MM, Leemans CR, Bloemena E, Heideman DAM, Braakhuis BJM, Hesselink AT, et al. Increasing prevalence rates of HPV attributable oropharyngeal squamous cell carcinomas in the Netherlands as assessed by a validated test algorithm. Int J Cancer. (2013) 132:1565-71. doi: 10.1002/ijc.27821

35. Colletier PJ, Garden AS, Morrison WH, Goepfert H, Geara F, Ang KK. Postoperative radiation for squamous cell carcinoma metastatic to cervical lymph nodes from an unknown primary site: outcomes and patterns of failure. Head Neck. (1998) 20:674-81. doi: 10.1002/(SICI)10970347(199812)20:8<674::AID-HED3>3.0.CO;2-H

36. Reddy SP, Marks JE. Metastatic carcinoma in the cervical lymph nodes from an unknown primary site: results of bilateral neck plus mucosal irradiation vs. ipsilateral neck irradiation. Int J Radiat Oncol Biol Phys. (1997) 37:797802. doi: 10.1016/S0360-3016(97)00025-4

37. Ligey A, Gentil J, Créhange G, Montbarbon X, Pommier P, Peignaux K, et al. Impact of target volumes and radiation technique on loco-regional control and survival for patients with unilateral cervical lymph node metastases from an unknown primary. Radiother Oncol. (2009) 93:4837. doi: 10.1016/j.radonc.2009.08.027

38. Erkal HS, Mendenhall WM, Amdur RJ, Villaret DB, Stringer SP. Squamous cell carcinomas metastatic to cervical lymph nodes from an unknown head-and-neck mucosal site treated with radiation therapy alone or in combination with neck dissection. Int J Radiat Oncol Biol Phys. (2001) 50:55-63. doi: 10.1016/S0360-3016(00)01554-6
39. Strojan P, Ferlito A, Langendijk JA, Corry J, Woolgar JA, Rinaldo A, et al. Contemporary management of lymph node metastases from an unknown primary to the neck: II. A review of therapeutic options. Head Neck. (2013) 35:286-93. doi: 10.1002/hed.21899

40. Löning $\mathrm{T}$, Ikenberg $\mathrm{H}$, Becker J, Gissmann L, Hoepfer I, zur Hausen H. Analysis of oral papillomas, leukoplakias, and invasive carcinomas for human papillomavirus type related DNA. J Invest Dermatol. (1985) 84:417-20. doi: 10.1111/1523-1747.ep122 65517

41. Gillison ML, Chaturvedi AK, Anderson WF, Fakhry C. Epidemiology of human papillomavirus-positive head and neck squamous cell carcinoma. $J$ Clin Oncol. (2015) 33:3235-42. doi: 10.1200/JCO.2015.61.6995

42. Graboyes EM, Sinha P, Thorstad WL, Rich JT, Haughey BH. Management of human papillomavirus-related unknown primaries of the head and neck with a transoral surgical approach. Head Neck. (2015) 37:160311. doi: $10.1002 /$ hed. 23800

43. Begum S, Gillison ML, Ansari-Lari MA, Shah K, Westra WH. Detection of human papillomavirus in cervical lymph nodes: a highly effective strategy for localizing site of tumor origin. Clin Cancer Res. (2003) 9:64 69-75.

44. Begum S, Gillison ML, Nicol TL, Westra WH. Detection of human papillomavirus-16 in fine-needle aspirates to determine tumor origin in patients with metastatic squamous cell carcinoma of the head and neck. Clin Cancer Res. (2007) 13:1186-91. doi: 10.1158/1078-0432.CC R-06-1690

45. Zhang MQ, El-Mofty SK, Dávila RM. Detection of human papillomavirusrelated squamous cell carcinoma cytologically and by in situ hybridization in fine-needle aspiration biopsies of cervical metastasis: a tool for identifying the site of an occult head and neck primary. Cancer. (2008) 114:11823. doi: $10.1002 / \mathrm{cncr} .23348$

46. Park JM, Jung CK, Choi YJ, Lee KY, Kang JH, Kim MS, et al. The use of an immunohistochemical diagnostic panel to determine the primary site of cervical lymph node metastases of occult squamous cell carcinoma. Hum Pathol. (2010) 41:431-7. doi: 10.1016/j.humpath.2009.09.001

47. Schroeder L, Boscolo-Rizzo P, Dal Cin E, Romeo S, Baboci L, Dyckhoff G, et al. Human papillomavirus as prognostic marker with rising prevalence in neck squamous cell carcinoma of unknown primary: a retrospective multicentre study. Eur J Cancer. (2017) 74:73-81. doi: 10.1016/j.ejca.2016. 12.020

48. Müller von der Grün J, Bon D, Rödel C, Balermpas P. Patterns of care analysis for head \& neck cancer of unknown primary site: a survey inside the German society of radiation oncology (DEGRO). Strahlenther Onkol. (2018) 194:750-8. doi: 10.1007/s00066-018-1308-0

49. Isayeva $\mathrm{T}$, $\mathrm{Li} \mathrm{Y}$, Maswahu $\mathrm{D}$, Brandwein-Gensler M. Human papillomavirus in non-oropharyngeal head and neck cancers: a systematic literature review. Head Neck Pathol. (2012) 6 (Suppl 1):S104-20. doi: 10.1007/s12105-012-0368-1

50. Combes J-D, Franceschi S. Role of human papillomavirus in nonoropharyngeal head and neck cancers. Oral Oncol. (2014) 50:3709. doi: 10.1016/j.oraloncology.2013.11.004

Conflict of Interest: The authors declare that the research was conducted in the absence of any commercial or financial relationships that could be construed as a potential conflict of interest.

Copyright (C) 2019 Broglie, Dulguerov, Henke, Siano, Putora, Simon, Zwahlen, Huber, Ballerini, Beffa, Giger, Rothschild, Negri and Elicin. This is an open-access article distributed under the terms of the Creative Commons Attribution License (CC BY). The use, distribution or reproduction in other forums is permitted, provided the original author(s) and the copyright owner(s) are credited and that the original publication in this journal is cited, in accordance with accepted academic practice. No use, distribution or reproduction is permitted which does not comply with these terms. 